Biomedical
Research \& Therapy

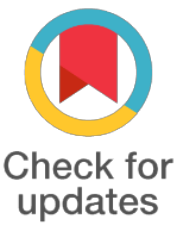

*For correspondence:

v.cuongn@vinmec.com

Competing interests: The authors declare that no competing interests exist.

Received: 2017-07-11

Accepted: 2017-08-19

Published: 2017-09-05

Copyright The Author(s) 2017. This article is published with open access by BioMedPress (BMP).

This article is distributed under the terms of the Creative Commons Attribution License (CC-BY 4.0) which permits any use, distribution, and reproduction in any medium, provided the original author(s) and the source are credited.

ORAL

\title{
Next-generation sequencing to evaluate frequency of BCR-ABL1 kinase domain Imatinib-resistance mutations
}

Chinh Q. Duong, Trang T. Nguyen, Lam V. Nguyen, Huy Q. Pham, Hien T. T. Trinh, Hoang C. Tran, Tuong Q. Le, Thanh H. Nguyen, Hai N. Truong, Tri A. Nguyen, Cuong Nguyen

Vinmec Research Institute of Stem Cell and Gene Technology, Hanoi, Vietnam

\section{Abstract}

Chronic myeloid leukemia is a clonal myeloproliferative neoplasm, characterized by the presence of chromosomal translocation $\mathrm{t}(9 ; 22)(\mathrm{q} 34 ; \mathrm{q} 11)$. This is found in over $95 \%$ of the cases and results in the BCR-ABL1 fusion gene with high tyrosine kinase activity. During the last decades, imatinib and other generation of tyrosine kinase inhibitors have been used effectively for target therapy of the disease. However, many of the drug resistance cases have been reported recently, due to the mutation within kinase domain of the BCR-ABL1 fusion gene. In this work, we performed a retrospective study of 141 imatinib-resistance chronic myeloid leukemia patients to analyze kinase domain mutation by deep sequencing. Another group of 20 untreated patients were added as control. RNA from bone marrow cells was extracted and deeply sequenced utilizing Illumina MiSeq. Bioinformatics pipeline was applied for variant calling and annotation. And the Sanger sequencing was used to validate those mutations. The results showed that nearly one-fourth of patients harboring mutations that resist to Imatinib, among those, $\mathrm{Y}_{253} \mathrm{~F} / \mathrm{H}, \mathrm{M}_{351} \mathrm{~T}, \mathrm{G}_{250 \mathrm{E}}, \mathrm{F}_{359} \mathrm{~V} / \mathrm{I}$ and $\mathrm{M}_{244 \mathrm{~V}}$ were the most frequent mutations. There were also a number of samples harboring multiple substitutions and new variations. Thus, Nextgeneration sequencing could be the sensitive and effective method to detect kinase domain mutation and our results could provide further information about the drug-resistance mutation in chronic myeloid leukemia.

\section{Keywords}

Chronic myeloid leukemia (CML), BCR-ABL1, imatinib resistance, tyrosine kinase inhibitor (TKI), kinase domain (KD), next-generation sequencing (NGS).

\section{Funding}

This work was supported by Vietnam Academy of Science and Technology (VAST) under the grant number: VAST02.05/15-16.

\section{References}

